\title{
Hop-induced formation of ethyl esters in dry-hopped beer
}

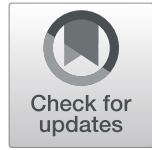

\author{
Sabrina Brendel', Thomas Hofmann ${ }^{1}$ and Michael Granvog ${ }^{2^{*}}$ (D)
}

\begin{abstract}
Fruity smelling esters play an important role for the aroma of hops and beer and they have been characterized as key aroma compounds in different hop varieties. Studies on the transfer of hop-derived compounds into beer during dry-hopping showed calculated transfer rates of different ethyl esters far above 100\%, leading to the assumption that these esters must be newly formed. To investigate this formation, dry-hopping was imitated in water to eliminate the influence of the beer matrix on the formation of these odorants. Thereby, the formation of ethyl esters of 2-methylbutanoic acid, 3-methylbutanoic acid, and methylpropanoic acid, induced by the addition of hops, was shown. Different approaches inhibiting enzyme activities and experiments with different hop extracts might lead to the assumption that enzymes are involved in the formation of these esters, beside possible transesterification.
\end{abstract}

Keywords: Hops, Dry-hopping, Beer, Ethyl esters, Aroma formation, Radicals, Enzymes

\section{Introduction}

Previous studies on dry-hopping have evaluated the transfer of, among other odorants, different ethyl esters from hops into beer. Thereby, calculated transfer rates far above 100\% were observed (Brendel et al. 2020; Neiens and Steinhaus 2019). It is already known that hops can be the source of monocarboxylic acids, that are needed for the formation of these esters, namely, 2- and 3-methylbutanoic acid and methylpropanoic acid, formed by the degradation of humulones (Rettberg et al. 2014; Williams and Wagner 1979). Thus, a subsequent esterification of the respective monocarboxylic acids with ethanol was assumed, but has not been verified by further investigations (Schnaitter et al. 2016a, b). In beer, different formation pathways of ethyl esters have already been suggested, e.g., a non-enzymatic reaction during beer storage (Vanderhaegen et al. 2003, 2007; Williams and Wagner 1978, 1979). Other studies have postulated the formation of ethyl esters via transesterification of other hop-derived esters like methylpropyl methylpropanoate,

\footnotetext{
* Correspondence: michael.granvogl@uni-hohenheim.de

${ }^{2}$ Institut für Lebensmittelchemie, Fg. Lebensmittelchemie und Analytische Chemie (170a), Universität Hohenheim, Fakultät für Naturwissenschaften, Garbenstraße 28, 70599 Stuttgart, Germany

Full list of author information is available at the end of the article
}

3-methylbutyl methylpropanoate, and 2-methylbutyl methylpropanoate during fermentation (Takoi et al. 2018; Forster and Gahr 2013). A further possibility is the enzymatic esterification during yeast fermentation by acetylCoA:ethanol $O$-acetyltransferases (AEATs) (Dank et al. 2018; Rettberg et al. 2014; Saerens et al. 2008). Two AEATs in yeast have already been identified as Eht1 and Eeb1, catalyzing a condensation of medium chain fatty acids with ethanol (Saerens et al. 2006; Mason and Dufour 2000). Isoleucine, leucine, and valine are known as precursors for 2-methylbutyl and 2-methylbutanoate esters, 3methylbutyl and 3-methylbutanoate esters, and methylpropyl and methylpropanoate esters (Matich and Rowan 2007; Rowan et al. 1996).

However, in a very recent study (Brendel et al. 2020), ethyl ester formation has mainly been observed in dryhopped samples, even if the concentrations of the respective monocarboxylic acids as precursors would have been high enough (in the same ranges as some of the dry-hopped beers) in the non-hopped reference samples. Due to the fact that the samples before and after dryhopping were stored under the same conditions and for the same time, ester formations should have taken place in both. Thus, only the transfers from acids into the beer, followed by their esterification cannot explain this

(c) The Author(s). 2020 Open Access This article is licensed under a Creative Commons Attribution 4.0 International License, which permits use, sharing, adaptation, distribution and reproduction in any medium or format, as long as you give appropriate credit to the original author(s) and the source, provide a link to the Creative Commons licence, and indicate if changes were made. The images or other third party material in this article are included in the article's Creative Commons licence, unless indicated otherwise in a credit line to the material. If material is not included in the article's Creative Commons licence and your intended use is not permitted by statutory regulation or exceeds the permitted use, you will need to obtain permission directly from the copyright holder. To view a copy of this licence, visit http://creativecommons.org/licenses/by/4.0/. 
phenomenon. On the other hand, yeast metabolism can also not be the origin of these ethyl esters, because then, no difference between the dry-hopped and non-hopped samples should have been obtained. If hops contain unknown AEATs, an enzymatic ester formation might be induced by hop addition into beer (Brendel et al. 2020).

Thus, this study should clarify the role of hops in the formation of ethyl esters and give hints on monocarboxylic acids or methylpropanoic acid esters as precursors within a possible transesterification. Therefore, model studies in water were performed to confirm the formation of the target esters and to exclude the influence of yeast enzymes on the reaction. To arrive at a more accurate picture, different hop extracts were used in the model system studies and different methods of enzyme inhibition should give deeper insights into the reaction type.

\section{Materials and methods Hop samples}

Hallertauer Mandarina Bavaria hop pellets type 90, harvest year 2015, were provided by Hopsteiner (Mainburg, Germany). Identification and quantitation of odorants in this batch have already been performed in a previous study (Brendel et al. 2019). Hop extracts were also provided by Hopsteiner: Alpha extract contained $20.0 \pm 1.0 \%$ $\alpha$-acids. Beta rich hop extract was specified with $40 \pm 0.2 \%$ $\beta$-acid content. XanthoFlav ${ }^{\text {Tw }}$ extract was coated on diatomaceous earth with a specification of $7-12 \%$ xanthohumol (without carrier material). Tannin extract contained 2-6\% low molecular weight polyphenols.

\section{Chemicals}

The following reference compounds were purchased from commercial sources: ethyl 2-methylbutanoate, ethyl 3-methylbutanoate, ethyl methylpropanoate, 2methylbutanoic acid, 3-methylbutanoic acid, and methylpropanoic acid (Sigma-Aldrich, Taufkirchen, Germany).

The following chemicals were obtained commercially: calcium chloride dihydrate, diethyl ether, ethanol, anhydrous sodium sulfate (Merck, Darmstadt, Germany); L-ascorbic acid (Sigma-Aldrich); and argon, helium, hydrogen, and nitrogen (Westfalen, Münster, Germany).

\section{Stable isotopically labeled internal standards}

The stable isotopically labeled internal standards were synthesized as previously described (Guth and Grosch 1993): $\left[{ }^{2} \mathrm{H}_{5}\right]$-ethyl 2-methylbutanoate, $\left[{ }^{2} \mathrm{H}_{9}\right]$-ethyl 3methylbutanoate, and $\left[{ }^{2} \mathrm{H}_{5}\right]$-ethyl methylpropanoate via esterification of the respective labeled carboxylic acid with ethanol.

\section{Isolation of the esters from hop extracts}

To hop extract $(0.1-1 \mathrm{~g})$, diethyl ether $(2 \times 100 \mathrm{~mL})$ and the stable isotopically labeled internal standards $(0.2-$ $0.8 \mu \mathrm{g}$, dissolved in ethanol; amounts depending on the concentration of the respective analyte, determined in preliminary experiments) were added. After equilibration, the sample was extracted by stirring for $2 \times 1.5 \mathrm{~h}$ at room temperature. The extract obtained was subjected to high vacuum distillation using the solvent assisted flavor evaporation (SAFE) technique (Engel et al. 1999). After drying over anhydrous sodium sulfate, the filtered sample was concentrated to $\sim 100 \mu \mathrm{L}$ using a Vigreux column $(50 \mathrm{~cm} \times 1 \mathrm{~cm}$ id), followed by microdistillation. The concentrated extract was used for two-dimensional high-resolution heart-cut gas chromatography-mass spectrometry (HRGC/HRGC-MS).

\section{Model system studies with hops}

For the dry-hopping model, water $(500 \mathrm{~mL})$, ethanol $(250 \mu \mathrm{L})$, hops $(0.8 \mathrm{~g})$, 2-methylbutanoic acid, 3methylbutanoic acid, and methylpropanoic acid $(250 \mu \mathrm{g}$ each) were used to prepare six different models: model A containing all compounds mentioned above; model B without hops; model $\mathrm{C}$ without ethanol; model D without carboxylic acids; model $\mathrm{E}$ without argon atmosphere; and model $\mathrm{F}$ in a clear glass bottle. The samples were stirred at room temperature for 10 days in amber glass bottles (except for model F) under argon (except for model E). The concentrations of the esters were measured via headspace solid phase microextraction comprehensive twodimensional high-resolution gas chromatography-time-offlight mass spectrometry (HS-SPME-HRGCxHRGC-TOFMS).

\section{Model system studies to evaluate the reaction type}

A further model in a clear glass bottle with the addition of ascorbic acid $(5 \mathrm{~g})$ as antioxidant was prepared (model G). Next, model A (as described above) was modified by the addition of calcium chloride $(5 \mathrm{~g})$ to evaluate the influence of enzyme activities (model $\mathrm{H}$ ) on the ester formation. For the next experiment, hops were heatprocessed in water under reflux for $20 \mathrm{~min}$ prior to the addition of ethanol and the acids (model I) to evaluate the influence of a heat treatment on a possibly enzymatic activity. The concentrations of the esters were analyzed again via HS-SPME-HRGCxHRGC-TOF-MS.

\section{Model system studies with hop extracts}

For each hop extract, two further models were prepared: water $(100 \mathrm{~mL})$, ethanol $(50 \mu \mathrm{L})$, and the respective hop extract $(0.15 \mathrm{~g})$ were stirred under argon in amber glass bottles for 10 days at room temperature, once without the addition of carboxylic acids (model $J$ ) and once with carboxylic acids $(250 \mu \mathrm{g}$ each) (model K). Again, the 
concentrations of the esters were measured via HSSPME-HRGCxHRGC-TOF-MS.

Two-dimensional high-resolution heart-cut gas chromatography-mass spectrometry (HRGC/HRGC-MS)

For quantitation of the esters in the hop extracts, HRGC/HRGC-MS was performed as recently described (Brendel et al. 2019).

\section{Headspace solid phase microextraction-comprehensive two-dimensional high-resolution gas chromatography- time-of-flight mass spectrometry (HS-SPME-HRGCxHRGC- TOF-MS)}

To an aliquot of the aqueous samples $(50 \mathrm{~mL})$, the stable isotopically labeled internal standards (10-35 ng, dissolved in ethanol; amounts depending on the concentration of the respective analyte, determined in preliminary experiments) were added and the mixture was stirred for $15 \mathrm{~min}$ at room temperature for equilibration. An aliquot $(5 \mathrm{~mL})$ and sodium chloride $(2 \mathrm{~g})$ were filled into a headspace vial $(20 \mathrm{~mL})$ and the measurements were performed as previously described (Brendel et al. 2020).

\section{Results and discussion}

Model system studies with hops

The study setup using water, ethanol, hops, and monocarboxylic acids was chosen to simulate the dry-hopping process and to exclude the possible influence of the beer matrix with yeast enzymes on the formation of the odorants. By performing the experiments with an alcohol content of $0.05 \%$ vol, also alcohol-free beers can be included into the resulting considerations, for which an ester formation has also been observed (Brendel et al. 2020). Therefore, the study should also answer the question whether this low alcohol content, that for instance can be reached via thermal dealcoholization, is sufficient for esterification.

Figure 1 shows the results of all models, for which hop pellets were used, in comparison to the concentrations of the respective esters in the used amount of hops. All models are compared to model A (consisting of water, ethanol, hops, and acids in an amber glass bottles under argon), which functions as a dry-hopping model without any additives or special treatments. Already the comparison of the results obtained for model A $(0.37-2.3 \mu \mathrm{g} / \mathrm{L})$ to the concentrations of ethyl esters in hop pellets

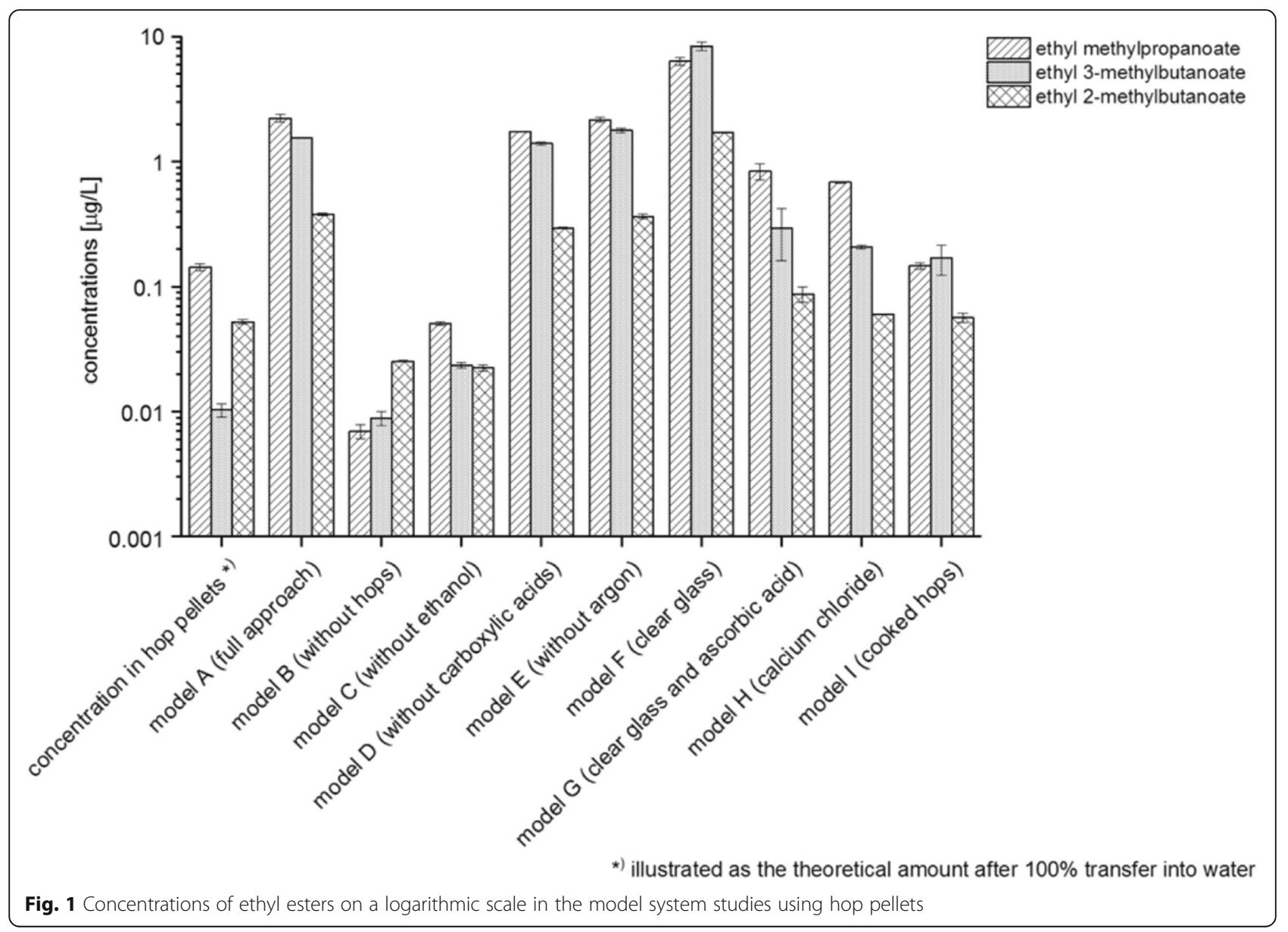


(6.9-96 $\mu \mathrm{g} / \mathrm{kg}$, which is equivalent to $0.011-0.15 \mu \mathrm{g} / \mathrm{L}$, based on a theoretical $100 \%$ transfer from hops into water) underlines the hypothesis, that a formation of these esters is caused by the addition of hops due to their clearly increased concentrations. In contrast, the esterification of the added carboxylic acids with ethanol without hop addition (model B) was clearly lower $(0.007-0.025 \mu \mathrm{g} / \mathrm{L})$ than in the dry-hopped approach (model A). This experiment also showed that the fermentation process and the activity of yeast enzymes is not relevant for the observed formation of ethyl esters in real beer samples. As a control, the model without ethanol (model C) showed ester concentrations in the same range as the concentrations in the used hop pellets, showing an ester transfer during dry-hopping.

Interestingly, the added monocarboxylic acids in model A did not influence the ester formation since their concentrations $(0.29-1.8 \mu \mathrm{g} / \mathrm{L})$ did not change significantly without the addition of the acids (model D). These results indicated that monocarboxylic acids derived from hop humulones and lupulones may not be the precursors for the esterification. Also Takoi et al. concluded that the concentrations of the formed esters should be much higher, if they are formed from the respective acids, as there is a high excess of hop bitter acids in beer (Takoi et al. 2018). Thus, a transesterification of other hop-derived esters seems to be more likely than the esterification of ethanol with hop-derived acids.

It has already been shown that also methyl 2methylbutanoate is formed during dry-hopping of (alcohol-free) beer (Brendel et al. 2020; Neiens and Steinhaus 2019). This increase interferes with a possible decrease of methyl ester concentrations by transesterification to ethyl esters, and thus, cannot be used as indicator for the ethyl ester formation. The same behavior could be shown by a semi-quantitative estimation of the contents of methyl 3-methylbutanoate and methyl methylpropanoate in hops and dry-hopped beer (data not published). However, also 2-methylbutyl methylpropanoate, 3methylbutyl methylpropanoate, and methylpropyl methylpropanoate have been postulated as precursors for the formation of ethyl esters in beer (Forster and Gahr 2013). These esters have been identified in different hop varieties and dry-hopped beer (Forster and Gahr 2013, 2014; Schmidt and Biendl 2016). Thereby, transfer rates of 40$72 \%$ were reported during dry-hopping with Hallertauer Cascade and Hallertauer Mandarina Bavaria and, therefore, the remaining $28-60 \%$ might be transesterified to ethyl esters (Forster and Gahr 2013, 2014). On the other hand, after dry-hopping with Hallertauer Huell Melon, Hallertauer Blanc, and Hallertauer Polaris, transfer/formation rates up to $161 \%$ (3-methylbutyl methylpropanoate) and $222 \%$ (2-methylbutyl methylpropanoate) were observed (Forster and Gahr 2013), and thus, these esters did not seem to be the precursors of ethyl esters, or these esters did show even higher transfer/formation rates and were partially transesterified to ethyl esters.

In previous studies, the concentrations of 2-methylbutyl methylpropanoate (40-300 mg/kg), 3-methylbutyl methylpropanoate $(10-40 \mathrm{mg} / \mathrm{kg})$, and methylpropyl methylpropanoate $(10-120 \mathrm{mg} / \mathrm{kg}$ ) were quantitated in Hallertauer Mandarina Bavaria, Hallertauer Cascade, and Hallertauer Mittelfrüh (Forster and Gahr 2013, 2014). The concentrations were much higher compared to those of the investigated ethyl esters in the hop varieties of the present study, with a maximum concentration of $96 \mu \mathrm{g} / \mathrm{kg}$ (Brendel et al. 2019). In beer, concentrations of $22-26 \mu \mathrm{g} / \mathrm{L}$ (3-methylbutyl methylpropanoate), 32-63 $\mu \mathrm{g} / \mathrm{L}$ (methylpropyl methylpropanoate), and 200-340 $\mathrm{\mu g} / \mathrm{L}$ (2-methylbutyl methylpropanoate) were reported (Forster and Gahr 2013, 2014).

In the model experiments, the concentrations of possible "precursor esters", e.g., 2-methylbutyl methylpropanoate and methylpropyl methylpropanoate, were semiquantitated (due to the missing corresponding labeled standard) in model $\mathrm{A}$ and model $\mathrm{C}$ using the concentration of ethyl methylpropanoate as a reference value (Table 1 ).

While the concentration of ethyl methylpropanaote was much higher in model A compared to model C (without ethanol), the related esters 2-methylbutyl methylpropanoate and methylpropyl methylpropanoate only showed a slight and not significant increase in their concentrations from model C to model A (Table 1). Furthermore, based on literature data, the estimated concentrations correspond to a transfer from hops into the solution of $<100 \%$, so the differences can also be caused by a variability of transfer (Forster and Gahr 2013). In the case of transesterification of the precursor esters to the corresponding ethyl esters, the precursor concentrations should be higher in model C. But as the formed amount of ethyl methylpropanoate is quite low related to the concentrations of the possible precursor esters, the possibility of transesterification cannot be excluded based on this semiquantitative data.

The presence of oxygen (model E without argon atmosphere) did not show any effects on the amount of

Table 1 Quantitative data of ethyl methylpropanoate and semiquantitative data of the possible precursor esters 2-methylbutyl methylpropanoate and methylpropyl methylpropanoate in model $\mathrm{A}$ and model $\mathrm{C}$

\begin{tabular}{llll}
\hline Sample & \multicolumn{3}{l}{ Concentrations $[\mu \mathrm{g} / \mathrm{L}]$} \\
\cline { 2 - 4 } & $\begin{array}{l}\text { ethyl } \\
\text { methylpropanoate }\end{array}$ & $\begin{array}{l}\text { 2-methylbutyl } \\
\text { methylpropanoate }\end{array}$ & $\begin{array}{l}\text { methylpropyl } \\
\text { methylpropanoate }\end{array}$ \\
\hline Model A & 2.2 & 140 & 46 \\
Model C & 0.05 & 110 & 43 \\
\hline
\end{tabular}


the formed esters $(0.36-2.2 \mu \mathrm{g} / \mathrm{L})$. Next, the influence of light on the formed amounts of esters was analyzed using a clear glass bottle (model F). Thereby, the ester formation increased by a factor of $3-5$ to $1.7-8.3 \mu \mathrm{g} / \mathrm{L}$, which might be a hint to a radical mechanism in ester formation. To reduce radical, but also enzymatic reactions, the clear glass sample was additionally treated with ascorbic acid (model G), which has antioxidative properties and influences the $\mathrm{pH}$ value as well. With this approach, the ester concentrations decreased by $62-81 \%$ to $0.087-0.84 \mu \mathrm{g} / \mathrm{L}$. Normally, a lower $\mathrm{pH}$ value should lead to a faster formation of esters of monocarboxylic acids and ethanol and also to a faster transesterification. If the reaction occurs due to an enzymatic activity, the respective enzymes can be inhibited by a suboptimal $\mathrm{pH}$ value. Possibly, beside the change of the $\mathrm{pH}$ value of the solution, the influence of the antioxidant properties of ascorbic acid on the reaction might be secondary, as hops already contain antioxidants like xanthohumol and other polyphenols.

To further test the involvement of enzymatic reactions, heat treatment and salt addition was used to decrease the enzymatic activity. Using calcium chloride (model
$\mathrm{H}$ ), the ester concentrations decreased by $69 \%$ for ethyl methylpropanoate $(0.68 \mu \mathrm{g} / \mathrm{L})$, by $84 \%$ for ethyl 2 methylbutanoate $(0.06 \mu \mathrm{g} / \mathrm{L})$, and by $87 \%$ for ethyl 3 methylbutanoate $(0.21 \mu \mathrm{g} / \mathrm{L})$. Also a heat treatment of the hops (model I) for a thermal inactivation of enzymes prior to the addition of ethanol decreased the ester concentrations by $85 \%$ for ethyl 2-methylbutanoate $(0.06$ $\mu \mathrm{g} / \mathrm{L})$, by $89 \%$ for ethyl 3-methylbutanoate $(0.17 \mu \mathrm{g} / \mathrm{L})$, and by $93 \%$ for ethyl methylpropanoate $(0.15 \mu \mathrm{g} / \mathrm{L})$. Thus, hops that is added during wort boiling may not have this ester formation activity. Since the addition of calcium chloride and an elevated temperature showed a clear impact on the ester formation, it can be postulated that the formation is induced by enzymes that are present in hops.

\section{Model system studies with hop extracts}

While the addition of monocarboxylic acids did not show an effect on the ester formation in the model studies above, performing the same model approach with different hop extracts did show an influence of acids on the formation of the ethyl esters (Fig. 2). A clear increase in the ester concentrations was found for alpha and beta

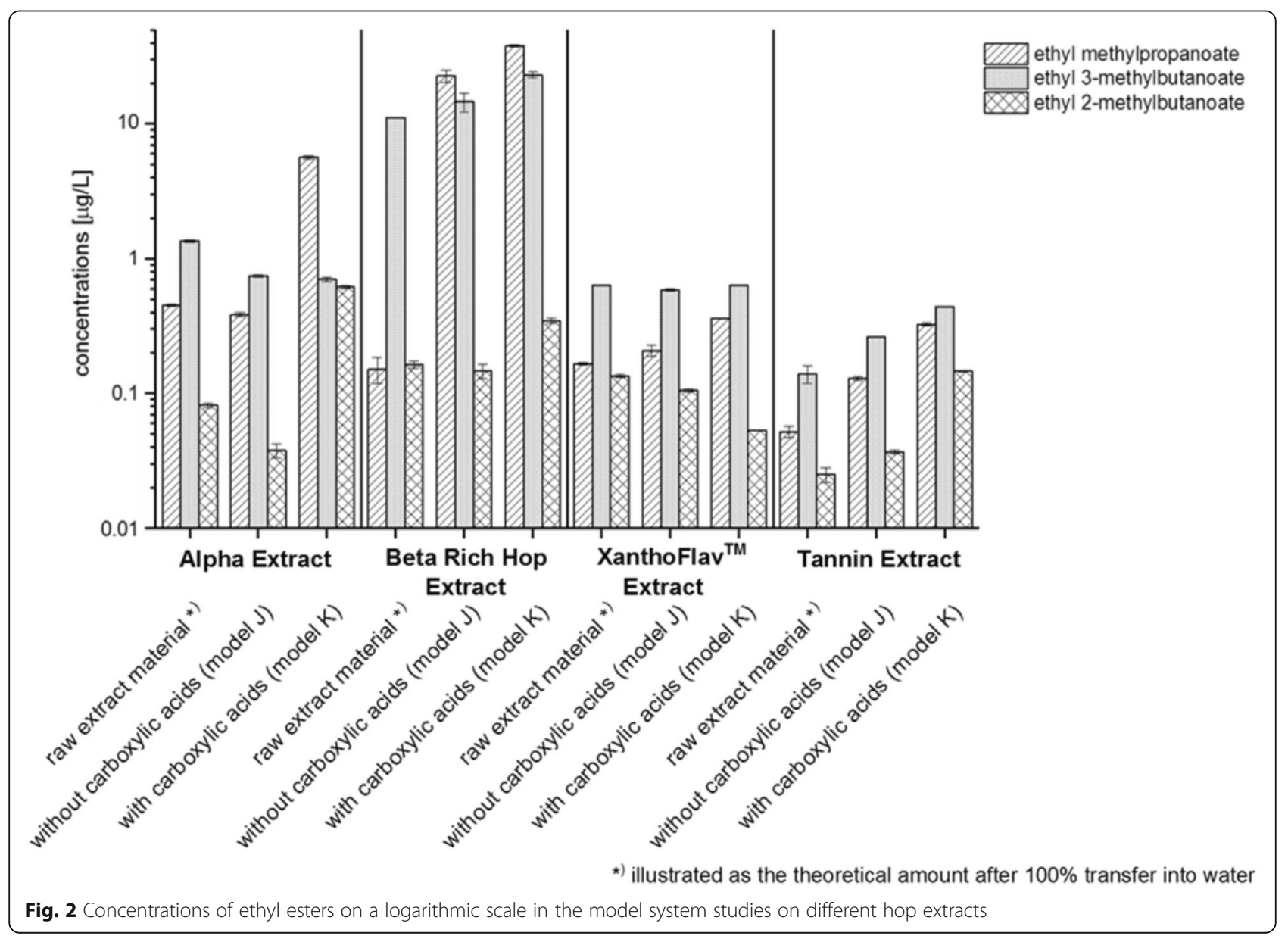


Table 2 Concentrations of newly formed ethyl esters in the model studies with different hop extracts

\begin{tabular}{|c|c|c|c|c|}
\hline \multirow[t]{2}{*}{ Extract } & \multirow{2}{*}{$\begin{array}{l}\text { Acid } \\
\text { addition }\end{array}$} & \multicolumn{3}{|l|}{ Concentrations $[\mu \mathrm{g} / \mathrm{L}]^{a}$} \\
\hline & & ethyl methylpropanoate & ethyl 3-methylbutanoate & ethyl 2-methylbutanoate \\
\hline \multirow[t]{2}{*}{ Alpha Extract } & no & 0.084 & $<\mathrm{LOD}^{b}$ & $<\mathrm{LOD}^{b}$ \\
\hline & yes & 5.7 & 0.70 & 0.62 \\
\hline \multirow[t]{2}{*}{ Beta Extract } & no & 22 & 7.1 & 0.037 \\
\hline & yes & 38 & 23 & 0.35 \\
\hline \multirow[t]{2}{*}{ XanthoFlav ${ }^{\mathrm{TM}}$ Extract } & no & 0.097 & 0.17 & 0.016 \\
\hline & yes & 0.36 & 0.63 & 0.053 \\
\hline \multirow[t]{2}{*}{ Tannin Extract } & no & 0.094 & 0.17 & 0.020 \\
\hline & yes & 0.32 & 0.44 & 0.15 \\
\hline
\end{tabular}

${ }^{a}$ Calculated as the difference between total ester content of the model samples and content in the used amount of hop extract

${ }^{b}$ Limit of detection (LOD) was determined based on a signal-to-noise ratio of 3: ethyl methylpropanoate 12 ng/L, ethyl 3-methylbutanoate 21 ng/L, and ethyl

2-methylbutanoate $61 \mathrm{ng} / \mathrm{L}$

extracts (both containing bitter acids), whereas the models treated with xanthohumol or tannin extracts did only show low rates of ester formation. However, the alpha and beta extracts cannot be directly compared, as they did not have an equal bitter acid concentration. Furthermore, the beta extract also had a residual content of $\alpha$-acids of $0.5 \%$. Therefore, they differ in their potential to release the respective monocarboxylic acids. It is also unknown, how effective the ethyl esters, that are already present in the hop extracts, are transferred into the aqueous system, as the extracts showed different textures and solubility in water.

Overall, the xanthohumol and tannin extracts showed the lowest ester formation activity, also if carboxylic acids were added. These models with xanthohumol and tannin extracts did not exceed the concentrations of formed esters (total concentration minus the potential transfer from the extract) of $0.63 \mu \mathrm{g} / \mathrm{L}$ (ethyl 3methylbutanoate in the xanthohumol extract with the addition of acids). Without the addition of acids, the xanthohumol and tannin extracts only formed 0.016$0.17 \mu \mathrm{g} / \mathrm{L}$ of the different esters (Table 2, Fig. 2). Also by estimating the concentrations of the possible "precursor esters" semi-quantitatively, the lowest amounts were observed in the xanthohumol extract.

The alpha extract showed nearly no ester formation activity, yielding not more than $0.08 \mu \mathrm{g} / \mathrm{L}$ (sum of all three ethyl esters), if no carboxylic acids were added. However, with the addition of carboxylic acids, especially the concentration of newly formed ethyl methylpropanoate increased to $5.7 \mu \mathrm{g} / \mathrm{L}$. The beta extract showed the highest activity already in the samples without acid addition $(22 \mu \mathrm{g} / \mathrm{L}$ ethyl methylpropanoate, $7.1 \mu \mathrm{g} / \mathrm{L}$ ethyl 3 -methylbutanoate). After adding the respective carboxylic acids, ester formation increased up to $38 \mu \mathrm{g} / \mathrm{L}$ (ethyl methylpropanoate) (Table 2, Fig. 2).

Generally, the highest formation rates of ethyl methylpropanoate and ethyl 3-methylbutanoate were observed in the beta extract, of ethyl 2-methylbutanoate in the alpha extract. The xanthohumol and tannin extracts only showed concentrations $<0.2 \mu \mathrm{g} / \mathrm{L}$ for each ester without the addition of carboxylic acids, but up to $0.63 \mu \mathrm{g} / \mathrm{L}$, if acids were added (Table 2, Fig. 2). In contrast to the models using hop pellets (A-I), an increase of esters was observed by adding monocarboxylic acids to the models with hop extracts (J and K).

\section{Conclusions}

In conclusion, the present study demonstrated that hops induce the formation of ethyl esters of 2- and 3methylbutanoic acid and methylpropanoic acid during dry-hopping. Thereby, also the residual alcohol content of alcohol-free beer is sufficient for this esterification. The reaction type cannot be clearly specified based on the performed model studies, but according to the inhibition of the reaction via $\mathrm{pH}$ value, heat treatment, and salt concentration, an enzymatic pathway can be postulated. Therefore, the transfer of these esters from hops into beer during dry-hopping is secondary, as the amounts of newly formed ethyl esters is much higher than their original contents in hops.

The question about the precursors of the ethyl esters could not fully be answered within this study, as by simulating dry-hopping with hop pellets, humulone- and lupulone-derived acids did not show a great influence on the concentration of ethyl esters, whereas in dryhopping models with hop extracts, the addition of these acids clearly led to higher concentrations of ethyl esters. Furthermore, other hop-derived esters as 2-methylbutyl methylpropanoate and methylpropyl methylpropanoate can also act as possible precursor structures for an ester formation via transesterification. As already reported earlier, this would be an important reaction regarding the sensory properties of the final product, as the odor thresholds of the ethyl esters are much lower compared to those of the "precursor esters" (Takoi et al. 2018). 


\section{Abbreviations}

AEAT: Acetyl-CoA:ethanol O-acetyltransferase; HRGC/HRGC-MS: Twodimensional high-resolution heart-cut gas chromatography-mass spectrometry; HS-SPME-HRGCXHRGC-TOF-MS: Headspace solid phase microextractioncomprehensive two-dimensional high-resolution gas chromatography-timeof-flight mass spectrometry

\section{Acknowledgements}

The authors thank Miss Ines Otte for her technical assistance.

\section{Authors' contributions}

Miss S. Brendel and Prof. Dr. M. Granvogl came up with the research question. S. Brendel investigated the analytical method, performed the measurements, evaluated the received data, and wrote the draft manuscript. M. Granvogl contributed in acquiring the research money, in supervising the full project, in discussing and interpreting the results, and in revising the manuscript. Prof. Dr. T. Hofmann supervised the project as owner of the chair at the Technical University of Munich, where the project was performed. The author(s) read and approved the final manuscript.

\section{Funding}

This IGF Project of the FEl was supported via AiF within the program for promoting the Industrial Collective Research (IGF) of the German Ministry of Economic Affairs and Energy (BMWi), based on a resolution of the German Parliament (AiF 18626 N).

\section{Availability of data and materials}

All needed data is presented in this manuscript. Other necessary data, that leaded to the underlying theory, has already been published and is cited at the corresponding position within this publication.

\section{Competing interests}

The authors declare that there is no competing interests.

\section{Author details}

'Lehrstuhl für Lebensmittelchemie und Molekulare Sensorik, Technische Universität München, Wissenschaftszentrum Weihenstephan für Ernährung, Landnutzung und Umwelt, Lise-Meitner-Straße 34, 85354 Freising, Germany ${ }^{2}$ Institut für Lebensmittelchemie, Fg. Lebensmittelchemie und Analytische Chemie (170a), Universität Hohenheim, Fakultät für Naturwissenschaften, Garbenstraße 28, 70599 Stuttgart, Germany.

Received: 22 March 2020 Accepted: 20 July 2020

Published online: 18 August 2020

\section{References}

Brendel, S., Hofmann, T., \& Granvogl, M. (2019). Characterization of key aroma compounds in pellets of different hop varieties (Humulus Lupulus L.) by means of the sensomics approach. Journal of Agricultural and Food Chemistry, 67, 12044-12053.

Brendel, S., Hofmann, T., \& Granvogl, M. (2020). Dry-hopping to modify the aroma of alcohol-free beer on a molecular level. Journal of Agricultural and Food Chemistry accepted. https://doi.org/10.1021/acs.jafc.0c01907.

Dank, A., Smid, E. J., \& Notebaart, R. A. (2018). CRISPR-Cas genome engineering of esterase activity in Saccharomyces cerevisiae steers aroma formation. BMC Research Notes, 11, 682

Engel, W., Bahr, W., \& Schieberle, P. (1999). Solvent assisted flavour evaporation a new and versatile technique for the careful and direct isolation of aroma compounds from complex food matrices. European Food Research and Technology, 209, 237-241.

Forster, A., \& Gahr, A. (2013). On the fate of certain hop substances during dry hopping. BrewingScience, 66, 93-103.

Forster, A., \& Gahr, A. (2014). A comparison of the analytical and brewing characteristics of Cascade and Comet hop varieties as grown in Yakima (USA) and Hallertau (Germany). BrewingScience, 67, 137-148.

Guth, H., \& Grosch, W. (1993). Quantitation of potent odorants of virgin olive oil by stable-isotope dilution assays. Journal of the American Oil Chemists' Society, 70, 513-518.

Mason, A. B., \& Dufour, J.-P. (2000). Alcohol acetyltransferases and the significance of ester synthesis in yeast. Yeast, 16, 1287-1298.
Matich, A., \& Rowan, D. (2007). Pathway analysis of branched-chain ester biosynthesis in apple using deuterium labeling and enantioselective gas chromatography-mass spectrometry. Journal of Agricultural and Food Chemistry, 55, 2727-2735.

Neiens, S. D., \& Steinhaus, M. (2019). Investigations on the impact of the special flavor hop variety Huell Melon on the odor-active compounds in late hopped and dry hopped beers. Journal of Agricultural and Food Chemistry, $67,364-371$

Rettberg, N., Thoerner, S., Labus, A. B., \& Garbe, L.-A. (2014). Aroma active monocarboxylic acids - origin and analytical characterization in fresh and aged hops. BrewingScience, 67, 33-47.

Rowan, D. D., Lane, H. P., Allen, J. M., Fielder, S., \& Hunt, M. B. (1996). Biosynthesis of 2-methylbutyl, 2-methyl-2-butenyl, and 2-methylbutanoate esters in Red Delicious and Granny Smith apples using deuterium-labeled substrates. Journal of Agricultural and Food Chemistry, 44, 3276-3285.

Saerens, S. M. G., Verstrepen, K. J., Thevelein, J. M., \& Delvaux, F. R. (2008). Ethyl ester production during brewery fermentation: a review. Cerevisia, 33, 82-90.

Saerens, S. M. G., Verstrepen, K. J., van Laere, S. D. M., Voet, A. R. D., van Dijck, P., Delvaux, F. R., \& Thevelein, J. M. (2006). The Saccharomyces cerevisiae EHT1 and $E E B 1$ genes encode novel enzymes with medium-chain fatty acid ethyl ester synthesis and hydrolysis capacity. The Journal of Biological Chemistry, 281, 4446-4456.

Schmidt, C., \& Biendl, M. (2016). Headspace trap GC-MS analysis of hop aroma compounds in beer. BrewingScience, 69, 9-15.

Schnaitter, M., Kell, A., Kollmannsberger, H., Schüll, F., Gastl, M., \& Becker, T. (2016a). Scale-up of dry hopping trials: importance of scale for aroma and taste perception. Chemie Ingenieur Technik, 88, 1955-1965.

Schnaitter, M., Wimmer, A., Kollmannsberger, H., Gastl, M., \& Becker, T. (2016b). Influence of hop harvest date of the 'Mandarina Bavaria' hop variety on the sensory evaluation of dry-hopped top-fermented beer. Journal of the Institute of Brewing, 122, 661-669.

Takoi, K., Itoga, Y., Koie, K., Takayanagi, J., Kaneko, T., Watanabe, T., ... Nomura, M. (2018). Behaviour of hop-derived branched-chain esters during fermentation and unique characteristics of Huell Melon and Ekuanot (HBC366) hops. BrewingScience, 71, 100-109.

Vanderhaegen, B., Delvaux, F., Daenen, L., Verachtert, H., \& Delvaux, F. R. (2007). Aging characteristics of different beer types. Food Chemistry, 103, 404-412.

Vanderhaegen, B., Neven, H., Coghe, S., Verstrepen, K. J., Verachtert, H., \& Derdelinckx, G. (2003). Evolution of chemical and sensory properties during aging of top-fermented beer. Journal of Agricultural and Food Chemistry, 51, 6782-6790.

Williams, R. S., \& Wagner, H. P. (1978). The isolation and identification of new staling related compounds from beer. Journal of the American Society of Brewing Chemists, 36, 27-31.

Williams, R. S., \& Wagner, H. P. (1979). Contribution of hop bitter substances to beer staling mechanisms. Journal of the American Society of Brewing Chemists, 37, 13-19.

\section{Publisher's Note}

Springer Nature remains neutral with regard to jurisdictional claims in published maps and institutional affiliations.

Ready to submit your research? Choose BMC and benefit from:

- fast, convenient online submission

- thorough peer review by experienced researchers in your field

- rapid publication on acceptance

- support for research data, including large and complex data types

- gold Open Access which fosters wider collaboration and increased citations

- maximum visibility for your research: over $100 \mathrm{M}$ website views per year

At $\mathrm{BMC}$, research is always in progress.

Learn more biomedcentral.com/submission 